\title{
Searching for absents: The State of things for the Neets (young people Not in Education, Employment or Training) in Greece. An overview
}

\author{
Professor Nikos Papadakis \\ University of Crete, Greece \\ Professor Argyris Kyridis (Corresponding author) \\ Aristotle University of Thessaloniki, Greece \\ Aristotle University of Thessaloniki, School of Education \\ Department of Early Childhood Education, 54124, Thessaloniki, Greece \\ Email: akiridis@ nured.auth.gr
}

Antonis Papargyris

Researcher, Greek Public Opinion (GPO), Greece

Doi:10.5296/ jsr.v6i1.7228 URL: http://dx.doi.org/10.5296/ jsr.v6i1.7228

\begin{abstract}
Neets (young people Not in Education, Employment or Training) is a distinctive social group which includes all the major characteristics of a contemporary social pathogeny. In Europe, only a few pieces of research have been carried out in order to determine the population and its characteristics which consist this social group. We tried to investigate the formation of Neets in Greece and to determine the characteristics of the persons who could be categorized as Neet. The percentage of Neets, as demonstrated by the findings of the survey "Barometer of Absents", is particularly high in Greece. The biographical rupture which a NEET has suffered and the vulnerability which he/she undergoes do not prevent him/her from redrawing his/her life orbit and from highlighting broader proposals to address social vulnerability and mitigate social inequalities. The quantitative mapping of NEETs based also on specific demographic characteristics, as well as the recording of the qualitative characteristics of an undoubtedly multi-parametric phenomenon are leading to the conclusion that in Greece is required a combined, multi-layered and targeted intervention that can re-integrate Neets.
\end{abstract}

Keywords: Education, employment, training, formal education 


\section{Introduction}

The relatively newly constructed term Neets (young people not in education, employment or training) refers to the young people, who refrain from education, training and employment, i.e. they are absent from every major institutional care of the welfare State. Defining Neets in terms of the ages that includes, varies internationally. However the overriding definition in the EU refers to young people between 15-24 years old (see more about variations of the term in Papadakis (2013: 27). Most European countries use this definition and are based on Labour Force Survey data to measure the Neets (Eurofound 2012: 19-20). The Eurofound report identifies five main subgroups: the conventionally unemployed; the unavailable (i.e. young carers, the sick and disabled); the disengaged (including discouraged workers as well as other young people who are pursuing dangerous or asocial lifestyles); the opportunity-seekers; and the voluntary NEETs: "those young people who are travelling and those constructively engaged in other activities such as art, music and self-directed learning" (Eurofound, 2012:24). The more extended effort in order to define the term and the characteristics Neet has been made in the U.K. (see Furlong 2006; Yates and Payne 2006). It is worth noting that we have no national scale primary research in the EU, a situation that complicates the Neets phenomenon detection and the mapping of this socially vulnerable group's characteristics and attitudes, even numerous efforts have been made in order to determine risk factors that lead young people to become Neets (Bynner and Parsons, 2002; Furlong and Biggart,1999; Schoon, 2007; Hill, 2003). Popham (2003:8) stated that Neets are characterized by "low levels of aspiration and little motivation".

Neets in the Eu in 2008, compiled at $11 \%$ of the young people population from 15 to 24 year old. While in 2012 this percentage rose to $12.9 \%, 7.469 .100$ young (see Eurofound 2012: 1 \& 23). The States with the biggest problem are Bulgaria, Italy, Ireland, Spain and Greece (see Eurostat July 2012, ibid. in Eurofound 2012: 29), i.e. mainly the southern Europe countries and Ireland, which were the most affected by the international economic recession. All the above-mentioned countries showed increased rates of Neets (with the exception of Ireland, the rate remained almost unchanged) compared to 2009 (see European Commission 2011: 3). In the Neets population the majority are women, as are clearly those between the age 20 to 24 years old (see. specifically, Papadakis 2013). Also the majority of NEETs, aged 15-24 years old seems to have low educational level (see Eurofound 2012: 31) but that varies between European Union's Member States, with some countries showing high rates of Neets (over $25 \%$ ) with a higher education degree. This phenomenon occurs principally in Greece, Cyprus, Latvia and Romania (see. Eurofound 2012: 32). As has already been mentioned, in most European countries, the vast majority of Neets have low or moderate levels of education. Thus, low and medium skilled young people are much more at risk in falling into the Neet condition. Indeed, according to recent CEDEFOP data the situation of young people, especially those with low educational level, deteriorates, as between 2000-2010 the number of jobs for people with low education levels (up to graduation from lower secondary education) decreased by $21 \%$, while it is expected to fall further by $20.1 \%$ between 2010 and 2020 (see European Commission 2012: 57, and table 1). 
Table 1: Supply and demand in relation to skill level (education) in EU.

\begin{tabular}{|c|c|c|c|c|c|c|c|c|c|c|c|c|}
\hline & \multicolumn{6}{|c|}{ Demand for skalls } & \multicolumn{6}{|c|}{ Supply of skills } \\
\hline & \multicolumn{2}{|c|}{$\begin{array}{c}\text { High } \\
\text { Change (\%) }\end{array}$} & \multicolumn{2}{|c|}{$\begin{array}{l}\text { Medium } \\
\text { Change (\%) }\end{array}$} & \multicolumn{2}{|c|}{ Low } & \multicolumn{2}{|c|}{$\begin{array}{l}\text { High } \\
\text { Change (\%) }\end{array}$} & \multicolumn{2}{|c|}{$\begin{array}{l}\text { Medium } \\
\text { Change (\%) }\end{array}$} & \multicolumn{2}{|c|}{$\begin{array}{l}\text { Low } \\
\text { Change (\%) }\end{array}$} \\
\hline & $\begin{array}{c}2000 \\
2010\end{array}$ & $\begin{array}{c}2010 \\
2020\end{array}$ & $\begin{array}{c}2000 \\
2010\end{array}$ & $\begin{array}{c}2010 \\
- \\
2020\end{array}$ & $\begin{array}{l}2000 \\
2010\end{array}$ & $\begin{array}{c}2010 \\
- \\
2020\end{array}$ & $\begin{array}{l}2000 \\
2010\end{array}$ & $\begin{array}{c}2010 \\
- \\
2020\end{array}$ & $\begin{array}{c}2000 \\
- \\
2010\end{array}$ & $\begin{array}{c}2010 \\
- \\
2020\end{array}$ & $\begin{array}{l}2000 \\
2010\end{array}$ & $\begin{array}{c}2010 \\
- \\
2020\end{array}$ \\
\hline EU27 & 31.5 & 19.7 & 9.4 & 4.8 & -21.0 & -20.1 & $\mathbf{4 . 3}$ & 26.5 & 8.0 & 1.8 & -17.3 & -28.9 \\
\hline Begium & 28.4 & 16.3 & 21.4 & 13.5 & -28.3 & -19.4 & 31.5 & 19.7 & 25.1 & 11.5 & -25.2 & -31.7 \\
\hline Bulgaria & 20.8 & 10.0 & 25.3 & 3.1 & -26.8 & -24.0 & 19.2 & 8.2 & 3.7 & -0.9 & -31.5 & -34.9 \\
\hline Crech Republic & 38.6 & 30.3 & 2.3 & -3.0 & -34.9 & -15.1 & 47.6 & 46.2 & 0.9 & -6.3 & -40.2 & -47.5 \\
\hline Denmark & 23.9 & 13.0 & -22.5 & -14.9 & 33.3 & 20.8 & 38.7 & 20.7 & -18.6 & -13.3 & 7.6 & 4.0 \\
\hline Germany & 10.3 & 0.4 & 5.9 & 0.4 & -14.6 & -6.5 & 16.4 & 9.0 & 7.8 & -2.5 & -15.5 & -18.1 \\
\hline Estonia & 21.4 & 5.6 & -11.1 & 6.1 & -19.2 & 17.5 & 37.1 & 12.4 & -0.9 & -6.9 & -31.2 & -24.0 \\
\hline Ireland & 67.7 & 16.8 & 5.9 & 13.2 & -33.1 & -30.2 & 86.2 & 13.8 & 20.3 & 5.2 & -23.2 & -33.8 \\
\hline Greece & 47.1 & 22.0 & 15.2 & 15.9 & -13.4 & -24.4 & 51.1 & 24.6 & 12.7 & 11.3 & -16.0 & -26.7 \\
\hline Spoin & 50.0 & 26.2 & 51.5 & 32.2 & -17.6 & -32.2 & 66.9 & 23.1 & 69.4 & 30.1 & -3.9 & -39.3 \\
\hline France & 31.1 & 32.3 & 3.9 & 2.2 & -20.2 & -16.9 & 45.7 & 29.3 & 10.4 & 3.5 & -18.4 & -20.4 \\
\hline Italy & 44.0 & 21.6 & 22.8 & 13.1 & -16.1 & -18.2 & 56.5 & 34.5 & 19.5 & 13.2 & -18.4 & -25.5 \\
\hline Cyprus & 63.3 & 33.3 & 28.0 & 13.9 & -13.1 & -18.3 & 75.3 & 30.8 & 38.7 & 17.5 & -10.1 & -26.5 \\
\hline Latvia & 27.0 & 23.7 & -9.1 & -6.4 & -12.6 & 36. & 46.9 & 29.0 & 0.0 & -11.7 & -30.6 & -27.6 \\
\hline Lthuania & -10.7 & -9.0 & 14.7 & 17.2 & -47.2 & 4.9 & 5.0 & 3.0 & 12.0 & -0.2 & -61.0 & -40.7 \\
\hline Luxembou & 88.7 & 29.9 & 36.9 & 16.4 & 0.0 & -30.7 & 107.1 & 34.5 & 18.8 & 18.9 & -22.2 & -38.8 \\
\hline Hungary & 37.2 & 25.9 & -8.5 & -2.2 & -38.7 & -13.2 & 50.2 & 38.6 & 0.1 & -6.5 & -30.9 & -49.0 \\
\hline Malta & 81.8 & 22.5 & 44.0 & 36.1 & -11.0 & -20.2 & 95.7 & 37.8 & 46.4 & 31.7 & -13.0 & -37.9 \\
\hline Netherlands & 45.7 & 26.1 & -2.2 & -1.8 & -13.3 & -11.1 & 52.1 & 34.6 & 0.9 & -0.1 & -16.2 & -30.1 \\
\hline Austr & 43.7 & 31.1 & 4.5 & -1.7 & -5.7 & -9.4 & 62.2 & 51.2 & 5.4 & -6.9 & -10.7 & -229 \\
\hline Poland & 54.8 & 26.7 & 9.5 & -13.7 & -12.5 & -3.6 & 39.4 & 45.5 & -5.9 & -15.1 & -19.2 & -32.5 \\
\hline Portugs & 63.1 & 18.2 & 38.8 & 40.3 & -18.3 & -14.9 & 71.7 & 24.0 & 49.8 & 26.4 & -11.7 & -15.6 \\
\hline Romania & 13.8 & 27.1 & -1.7 & 0.8 & -46.5 & -17.2 & 359.6 & 71.4 & -26.6 & -17.8 & -0.3 & -22.9 \\
\hline Slovakia & 48.7 & 39.2 & 2.9 & -1.5 & -44.6 & -14.8 & 66.3 & 28.5 & 3.4 & -6.7 & -23.4 & -29.4 \\
\hline Slowenia & 56.4 & 25.5 & 0.2 & -5.7 & -29.7 & -15.6 & 66.6 & 40.5 & 0.4 & -3.8 & -36.7 & -41.6 \\
\hline Finland & 32.3 & 11.4 & 9.2 & 4.2 & -32.4 & -20.1 & 36.2 & 26.4 & 2.6 & -9.9 & -43.0 & -45.5 \\
\hline Sweden & 18.9 & 9.0 & 0.4 & 5.6 & -5.0 & 4.0 & 39.3 & 28.8 & 7.3 & -2.4 & -6.7 & -25.9 \\
\hline United Kingdom & 30.6 & 19.4 & 16.6 & 15.7 & -30.7 & -44.4 & 40.2 & 20.4 & 19.7 & 13.0 & -29.6 & -43.6 \\
\hline
\end{tabular}

Source: CEDEFOP skills forecasts (2012). Note: Percentage change in the number of posts in the labour market requiring the different qualification levels.

Source: CEDEFOP skills forecasts (2012) in European Commission, 2012: 57.

Also young immigrants and disabled people or young people with very serious mental or physical health problems and young people with poor family background are at high risk in entering the Neets category (see further Eurofound, 2012: 55-56, Kokkikos 2013 and Drakaki et al. 2013: 146).

Finally it is worth noting that for the OECD countries the problem appears even bigger: although for the period between 2000 and 2010 an overall decrease of $0.7 \%$ in the average percentage of NEETs in the OECD countries was witnessed, from 2008 until 2010, the percentage increased from $13.7 \%$ (2008) to $15.8 \%$ (2010) (see OECD: Education at a Glance: OECD, Indicators 2012 in International Labour Office, 2013: 90 and in detail about the situation in the countries of OECD (Papadakis 2013: 27-28).

Being a Neet has some serious consequences, such as: (a) Wage scarring (Gregg and Tominey, 2005), (b) Increased participation in crime (The Prince's Trust, 2007), (c) Reduced employability (Bell and Blanchflower, 2010), (d) Poorer well-being (The Prince's Trust, 2010) and (e) Reduced self-confidence (The Prince's Trust, 2010). The cost of being a Neet is high. High for the young people themselves, the society and the state (Godfrey et al., 2002). 


\section{The Greek State of affairs with regard to Neets.}

In our country until recently there was no research dealing with the Neets phenomenon. According to the recent Eurofound study, Greece belongs in the cluster of countries with high percentage of Neets, in which there is an inherent gender dimension, are inactive, have no particular work experience, are medium and highly educated and are particularly disheartened (Eurofound 2012: 39-40 and Drakakis et al. 2013: 148).

Here it should be pointed out that the necessity to investigate the characteristics, opinions and attitudes of Neets in the different national environments should not be confined to the presentation of subjective reality, but must extend to the relationship between subjective and objective reality. It is no coincidence that Eurofound's recent relative study on Neets has as its starting point the dramatic worsening of the employment situation in Europe, utilized as interpretative key for the intensity of the Neets phenomenon (cf. and Eurofound 2012: 5). Neets is a special social group which includes young people without a "choice biography" (Roberts 2010, 2011, 2012; Shildrick and MacDonald 2006; Woodman 2009; Coles, 1995; Furlong and Cartmel, 2004). According to MacDonald, while there is little doubt that "young people who are NEET can face a range of disadvantages" (my emphasis), it is also true that the category may include "emerging adults", who are simply better off and "experimenting with life-style choices, postponing firm occupational commitments, perhaps enjoying gap years" (MacDonald 2011:431). But we have to admit that the social group of Neets is characterized by an enormous heterogeneity. Furlong (2006:553) correctly points out that Neets as a social category is a "flawed concept", merging some "extremely disadvantaged" with others who are in fact "able to exercise choices" (Furlong 2006:553). Williamson (2005:13), argues that the label Neets became 'a crude proxy by which wider forms of 'social exclusion' may be defined'.

But what happens in reality regarding the Greek Neets;

In trying a first response to this question we will proceed with a "Barometer of Absents: the NEETs" study synopsis and an interpretation of its key findings. This project lasted 26 months, included 9 Working Sections and reached 23 deliverables. The survey, on which the main deliverables of the project are based included

- 2 stages of quantitative research on a national scale (the research's first stage sample size were 800 households and 784 interviews were conducted with the use of a written structured questionnaire, while in the second stage the sample were 3.500 households and 3.459 interviews were conducted in all prefectures of the country).

- and 2 stages of qualitative research (in total 129 semistructured and 15 narrative interviews, based on GPO's population distribution which is grounded on the Greek Statistical Office's data and with theoretical sampling criteria ${ }^{1}$ ).

\footnotetext{
1 The sample selection-research subjects in qualitative research was mainly based on theoretical sampling as it is proposed by Grounded Theory (see Strauss \& Corbin 1990: 176-193) and with emphasis on critical cases. It is thus about sampling based concepts that have a proven theoretical relevance to the - under development - theory
} 
It is worth noting here that the Barometer of Absents (as to some extent Eurofound also - see Eurofound, 2012: 27-139) emphasizes on the behavioral models (especially in relation to attitudes and opinions about the welfare State, the State structure, political system, etc.), on the relationship of Neets with training and the level of studies (as well as issues associated with the potential to be a dropout from the early educational system), on working experiences and the relationship with institutions and structures of training and employment, the effects on their biography from their life conditions (including health issues), the economic situation of Neets and the alternative sources of income support, their socialization and participation, their confidence in institutions, the proposals and opinions for their reintegration and with addressing their problems arising from their placing in the Neet situational category. Evidently it should be pointed out that in setting up the methodological strategy of the Barometer of Absents it was taken into account that the young people not taking part in education, training or employment constitute a phenomenon characterized by relevancy and heterogeneity, in the sense that the forms and the degree of social exclusion vary from society to society, from country to country, depending on the culture, standards, stereotypes and prejudices, expectations, rules, institutions, moral values, the standard of living and the degree of socio-economic and cultural evolution.

The main conclusions regarding the number and geographical distribution, the characteristics and components, the emergency dimensions of biography, the attitudes, opinions and proposals of Neets, are the following:

Neets in Greece reach the rate of 16.9\% (see. KEADIK \& 2013b GPO: 9), placing Greece among the first European countries regarding the Neets. The percentage of young people of the same age who work is $16,2 \%$, who study is $65,4 \%$ and who re in a training program is 1,5\% (Source: GPO \& KEADIK 2013: 9)

- It is worth noting that this main finding of the research "Barometer of Absents" converges with the corresponding evaluation of Eurofound, based on processing secondary elements (namely $17.4 \%$ according to Eurofound - see. Eurofound 2012: 29). This is a particularly troubling finding, "that directly challenges the grid of public policies, in order to give reliable answers" (Papadakis 2013: 8).

- Among the administrative districts of the country those displaying greater concentrations in percentages of NEETs out of the total, are Southern Aegean regions, Central Greece and the Ionian Islands. On the other hand very low rates in NEETs in

and the phenomenon being investigated, in order to collect data on what the research subjects do or do not do in terms of action / interaction, the variation of conditions giving meaning to behavior, their condition and their opinions, how the conditions concern them change, the consequences of their situation and conditions (as well as their actions) and the successful or not (including planned) strategies (see Strauss \& Corbin 1990: 176-177). Who the Neets are (characteristics), how they perceive their situation, what are their past and what their current conditions (e.g. experience of education or work experience, economic situation), and also what are their opinions and attitudes and what their strategies and their priorities, are not simply the result of the implementation of Grounded Theory in field research, but also vital parameters for an in-depth investigation of the profile of the Greek Neet. 
comparison to the nationwide average are showing the regions of Western Macedonia, Epirus, Thessaly and Attica (see. GPO \& KEADIK 2013: 10 and Pandis and Zagkos 2013: 112). Neets seem to congregate in island regions where the phenomenon of seasonal and temporary employment strongly dominates and the economy is based primarily on the tertiary production sector (South Aegean and Ionian Islands). In addition, it is noted that the District of Sterea Hellas has the largest accumulation of NEETs population in Greece (cf. Papargyris 2013: 151). The geographical areas of the country showing the largest rates of school failure (according to the school dropout rates and the rates of rejection from the promotion exams) are on a constant basis Crete, Ionian Islands, East Macedonia, Thrace and the Aegean Islands. At the same time, the recent KANEP/GSEE's relevant research on school leak shows that the Ionian Islands, the Cyclades, the Dodecanese, East Macedonia and Thrace, Samos and Ikaria, are areas requiring immediate intervention by the State. And it's really interesting that these regions have low educational development indicators even when at the same time are areas with high rates of economic growth. Decades of research have shown that these same areas had always lower rates of educational development either in reference to individual indicators or to separate indicators combined (Kyridis et al. 1995; Kyridis et al. 1998; Kyridis et al. 1999a; Kyridis et al. 1999b; Kyridis et al. 1999c; Kyridis \& Drossos, 2001; Kyridis, 1997. It is a fact that allows another explanation for the high concentration of Neets in the regions mentioned above.

Table 2. Geographical distribution of NEETs

\begin{tabular}{|l|c|}
\hline Administrative Regions & Percentage Of NEETs \\
\hline East Macedonia \& Thrace & $17,1 \%$ \\
\hline Central Macedonia & $19,1 \%$ \\
\hline West Macedonia & $13,6 \%$ \\
\hline Thessaly & $13,7 \%$ \\
\hline Ipeiros & $13,4 \%$ \\
\hline lonian & $20,9 \%$ \\
\hline Western Greece & $18,3 \%$ \\
\hline Sterea Hellas & $22,2 \%$ \\
\hline Peloponnesus & $19,1 \%$ \\
\hline North Aegean & $15,8 \%$ \\
\hline South Aegean & $27,4 \%$ \\
\hline Crete & $17,1 \%$ \\
\hline Attica & $13 \%$ \\
\hline Thessaloniki & $14,6 \%$ \\
\hline
\end{tabular}

Source: GPO \& KEADIK 2013: 10 


\section{Macrothink}

- The allocation of NEETs in the Regions appropriates to the corresponding breakdown of all of the relevant age group. It is worth noting that there is a limited correlation with the urbanity (see in detail Drakaki et al. 2013: 226 and GPO \& KEADIK 2013: 12). Based on empirical data, the degree of urbanity affects (to a very limited extent) the appearance and spread of the social phenomenon of NEETs in Greece. More specifically, while Neets come about most often in rural areas, based on findings from the second phase of quantitative research (discussed in GPO \& KEADIK 2013: 12), in the internal distribution among all Neets, they live at 51.5\% in urban areas and at 48.5\% in rural areas (cf. Pandis Zagkos \& 2013: 112). This "paradox" is perfectly explicable given the concentration of the population, mainly in urban areas. So eventually the NEETs living in urban areas seem to be numerically somewhat more. In conclusion the Neets appear "at a higher frequency in rural areas, but in absolute numbers, they are mainly living in urban centres" (Drakaki et al. 2013: 226). In each case the urbanity cannot be ignored nor considered a critical variable, such as age, household income and education level.

- Gender affects to some extent the possibility of inclusion in the category of NEET, since women are represented in the category of NEETs in greater proportion than men (see. GPO \& KEADIK 2013: 12 and 17, also Pandis \& Zagkos 2013:111 and Drakaki et al. 2013:226). More precisely the percentage of women who are Neets is slightly larger than that of men. In detail the percentage of women Neets stands at $17.4 \%$ compared with the general population of that age group, while in the case of men the rate is $16.5 \%$ (see GPO \& KEADIK 2013: 12, 17 and Graphs $2 \& 3$ ).

Chart 2: distribution of the General youth population and Neets by gender.

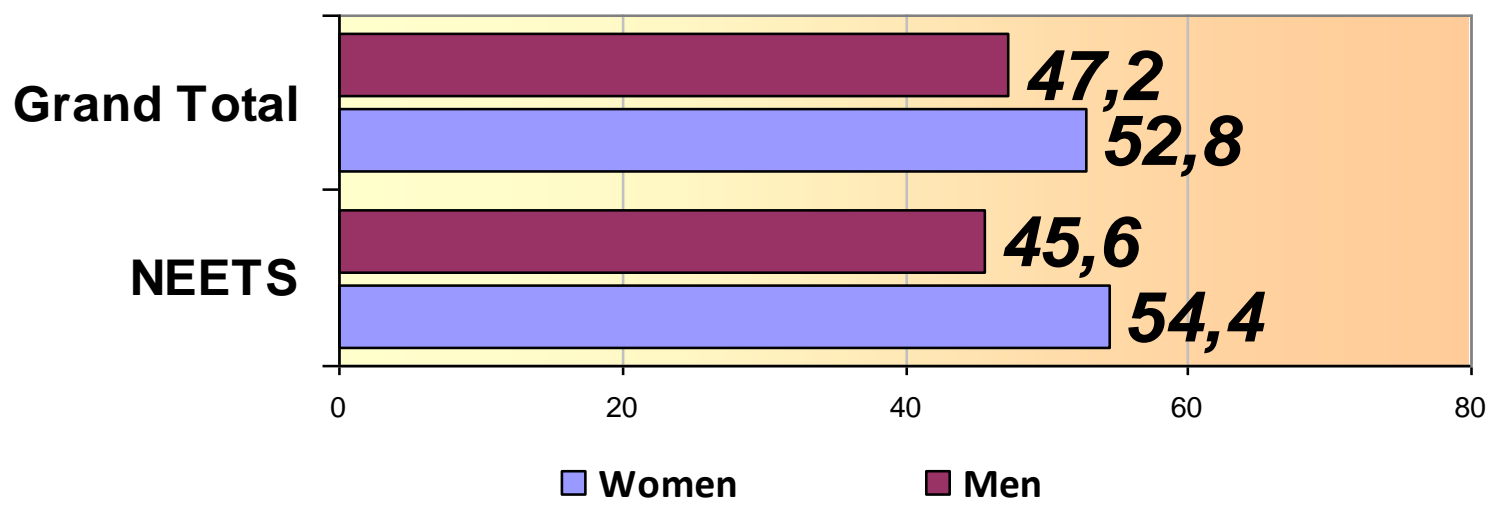

Source: GPO \& KEADIK 2013: 17. 


\section{Macrothink}

Chart 3: Distribution of Neets by gender, age, urbanity and family income.

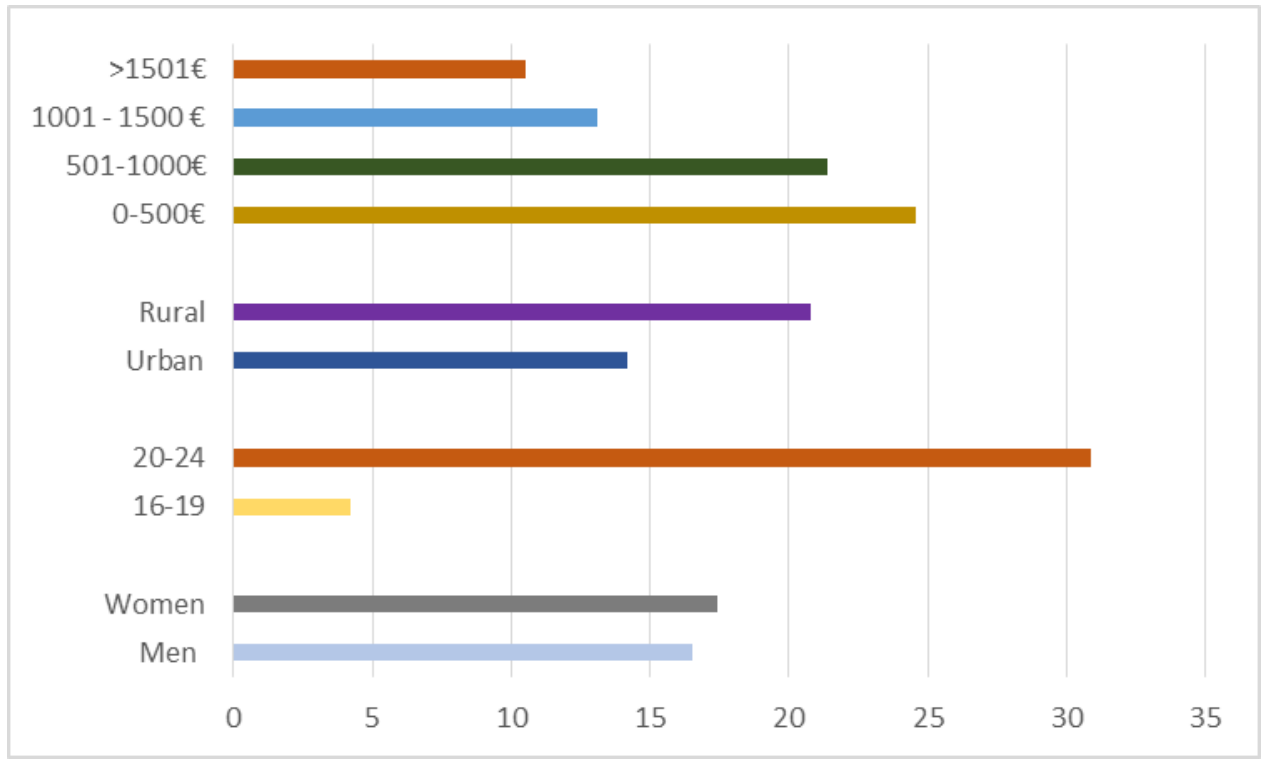

Source: GPO \& KEADIK 2013: 12.

In the internal allocation of Neets this means that $54.4 \%$ are women and $45.6 \%$ men, rates that also converge with the general distribution of the population group to which they belong, i.e. 52,8\% women against 47,2\% men (see GPO \& KEADIK 2013: 1217 and Pandis \& Zagkos 2013: 111). It seems that the gendered dimension is also present (albeit limited) in the problem of Neets, a situation not surprising in a society where by gender inequalities are acute and persistent (Tsakiridou et al. 2011). The above mentioned as well as the quantitative findings are also confirmed by the recent Eurostat statistics for April 2013 in relation to youth unemployment by gender. Specifically, in Greece, the percentage of youth unemployment for young people between 15-24 years old exceeded 59\% in 2013 (Eurostat, 2013), while the difference between female and male unemployment ranged in 2012 at $6.3 \%$ (Eurostat 2012: 242).

- Age is a main determinant, and perhaps the most important, affecting the chances of someone to be classed as NEET. Neets show their largest proportion in the age group of the 20-24 year olds, where the rate reaches $30.9 \%$ compared with $4.2 \%$ of the population (see GPO \& KEADIK 2013: 12 and Chart 3). In short, the vast majority of all Neets $(87.5 \%)$ belongs to the age group of $20-24$ years olds, while only $12.5 \%$ is younger (see also Pandis \& Zagkos 2013: 111-112). Age thus represents a par excellence over determinant of classification in the category of Neets. In addition it should be noted that, as demonstrated by the quantitative research, after the age of 22 , there is a rapid growth reaching up to $33 \%$ for the individuals aged 24 years old of the NEETS index (see GPO \& KEADIK 2012: 18). It is obvious that the relatively low rates of early school dropout and respectively the very high rates of completion of 
upper secondary education explain the low incidence of Neets in the younger age groups. Here it should be pointed out that in Greek society it is strongly observed the phenomenon of institutional extension of adolescence (Kelpanidis, 2000), which is due to two main factors: (a) the keeping children who become adults in the family residence, regardless the reasons of this choice (unemployment, obsessed with family, economic reasons) and (b) the at all costs continuation of studies and the non-integration into the labor market for study purposes. For these reasons, among others, the family protection even "unintentionally" contributes to young people's entrapment in a family enclave, which is transformed into a key tool of informal social protection, especially when the welfare State fails to actually protect. The data form a picture in which the phenomenon of NEETs seems to primarily relates to the older members of the age group, which allows us to deduce that the Greek family and the Greek society have managed to find the mechanisms that prevent young people of this specific group from marginalization, mechanisms that are not to the same extent present and do not cover as efficiently the ages $20-24$. In other words, the traditional social enclave of family undertakes the treating of social pathologies that "occur" to its members, assuming the role of "social protector" not only where when its members cannot be protected but also acting unsolicitedly. Based on all the aforementioned the existence of a social norm (the supportive role of the family) is emerging that plays a key role in the life of NEETs and which remains a crucial factor of support, with multi-level repercussions in the reconstruction of their disrupted life orbit.

- Regarding the ethno-cultural origins of Neets, it should be pointed out that as it was demonstrated by the quantitative research the total percentage of those not having the Greek nationality (immigrants and children of immigrants without Greek citizenship, i.e. people who have not been incorporated institutionally in Greece) is very small (see GPO \& KEADIK 2013: 27-28). We can speculate that the aforementioned low percentage does not reflect the actual percentage of young people having another nationality and that this particular demographic group is underrepresented. The interpretation of this under-representation is composed as follows: a) there is a large number of undocumented immigrants in the country and therefore they are difficult to identify and record in order reliable statistical data to be produced which could then serve as a reference point for our investigation, b) the absence of fixed telephone links for the members of this group and c) the inability to complete the questionnaire due to not understanding and not sufficiently knowing the Greek language.

- With regard to Neets' educational level and in accordance with the quantitative research data, for the largest percentage of this group's members who today are NEETS, they are graduates of lower (the smaller percentage) and higher (the majority of them) secondary education (High school, for the most part, or Vocational High School and Technical School), while is also significant the category of Neets who are tertiary education graduates (see. GPO \& KEADIK 2012: 33, Pandis \& Zagkos 2013: 113 and Chart 4). 
Chart 4: Educational levels of Neets.

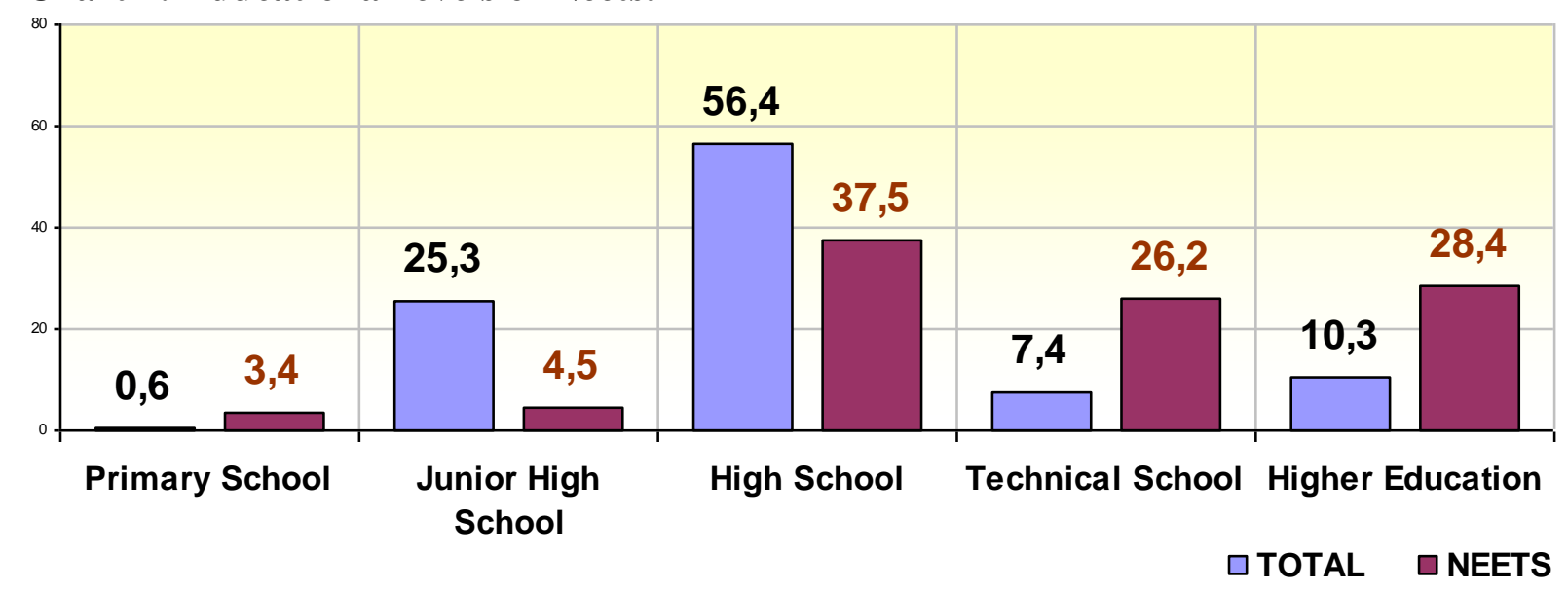

Source: GPO \& KEADIK 2012: 20

On this issue too there is a clear convergence between the findings of the "Barometer of Absents" study and that of Eurofound, which ranks Greece in the cluster of countries with a high proportion of Neets having high educational level (see Eurofound 2012: 32).

The second finding is quite interpretable in a country with $59.2 \%$ youth unemployment and particularly high unemployment of higher education graduates; and it is worth noting here that it is mainly the Neets/higher education graduates who are thinking very seriously of immigrating abroad (see Kotrogiannos et al. 2013: 194). A highly skilled workforce in an exceptionally productive age, which holds that has no hope of escape from this situation (a very strong finding in the qualitative research-see analytically KANEP \& KEADIK 2013: 35), it is not strange to delineate its future outside of Greece. It is worth mentioning that the proportion of Neets that have not completed general education is very low. Therefore, in Greece, it is not school dropout that determines the inclusion in Neet category (see Drakaki et al. 2013: 227). That case does exist, but eventually the educational level of the Greek Neets differs greatly from most European national cases. However, the majority of early dropouts (57.1\%) wishes to return and complete secondary education, with women, however, appearing more negative to such a prospect mainly alleging family reasons (see in more detail KEADIK \& KANEP 2012: 33). The correlation between the low/medium-skilled and inclusion in the category Neets is evident. Essentially, in an age where knowledge is the key development lever of all aspects of social life, we see the inflation of titles and diplomas keeping up with the ever expanded low educational indicators, school dropout, and the educational and cultural precipitation of entire regions. This reality constitutes a paradox which is illustrated by evidence from various directions (Pedagogical Institute, 2008 KANEP, 2009) markedly demonstrating both the deregulation of the educational mechanisms' traditional role and their inability to play, even marginally, their compensatory role in a "welfare" type educational policy. The rapid changes in the context of globalization have brought significant changes in the dipole education/training - labor market, thereby causing significant changes in the movement and flow of graduates from the educational field in the realm of employment. At the same time that the supply of specialties in relation to trends in 
demand lies in perpetual imbalance and irrational correlation, the unemployment among young people (15-24) increases significantly, the ever standing requested of the educational policy for the cultivation of culture and civilization within the school, but mainly the treatment of skill mismatch between those the educational system develops and the skills that the labor market needs, is required more than ever, to be a focal point of an education reform. Neets themselves blame the educational system for inefficiency (see Kotrogiannos et al. 2013: 183-185), dissociation from the labor market, emphasis on knowledge and not on skills. Switching to a competence-based learning environment shows persistently necessary. In any case the high percentage of higher education graduates that are Neets $(28.4 \%$ of Neets are graduates-see Graph 4) cannot be ignored, and that is something that should be widely associated with the high rate of higher education graduates' unemployment in Greece, as had already been stated. According to a recent survey of KANEP/GSEE, the unemployment in this labor force group has increased by 188\%, the period 2008-2012 (KANEP/GSEE, 2013). This fact raises important questions about the contents of university education. All of the above combined with the situation right now in Greece around the issue of unemployment especially that of young people - are wearying the productive fabric of the country, ruling out one of the most dynamic and capable group of Greek society. It seems that been a young NEET in Greece is not a product of choice and free will - like maybe (deemed) occurs in some other countries, but a result of a deadlock in the economic, social, educational and political situation (see Drakakis et al. 2013: 231 and Fotopoulos 2010: 4). The above-mentioned working hypothesis confirmed by Neets themselves, who in their vast majority identify themselves as unemployed, i.e. as active individuals, who are trying to find a job but do not succeed, while just a $6.8 \%$ spontaneously reply that this specific period "does nothing" (see in detail GPO \& KEADIK 2012: 34). Are the ones who in line with the international literature can be characterized as «freeters» ${ }^{2}$. Characteristic is the fact that in qualitative research, 13 out of 144 interviewees state that they are not seeking work (see KEADIK \& KANEP 2013: 18 and Kotrogiannos et al 2013: 188), which is probably due to the formation of behavioral characteristics derived from the microcosm of family environment. It cannot therefore be ignored the proportion of Neets, which have answered that they do not intend to do anything in order to address the problem of social vulnerability which they are facing. Therefore, it is particularly important the activation of State structures not only to tackle the problems of unemployment but also for the general mobilization of young people, facing similar problems, through targeted integration policies.

- Of particular interest is the fact that the majority of Neets live in households with low or very low income (as demonstrated by the quantitative research-see in detail GPO \& KEADIK 2012: 27 and GPO \& KEADIK 2013: 24-25 ${ }^{3}$ ). More specifically, $46 \%$ of Neets come from families with very low income (less than 1000 euros), while $13.1 \%$ from families with monthly income of 1000-1500 euros. At the same time there are no Neets in families with high income, over 3000 euros (see in detail GPO \& KEADIK 2012:27 and table 3).

\footnotetext{
${ }^{2}$ More on the conceptualization of freeters see in Inui, 2009 and Papadakis, 2013.

3 Noteworthy, however, is the percentage of Neets not knowing the monthly income of their family.
} 
Table 3: Neets family income

\begin{tabular}{lr}
\hline $0-500 €$ & $\mathbf{1 4 , 9}$ \\
\hline $501-1.000 €$ & $\mathbf{2 6 , 2}$ \\
\hline $1.001-1.500 €$ & $\mathbf{1 1 , 1}$ \\
\hline $1.501-2.000 €$ & $\mathbf{4 , 6}$ \\
\hline $2.001-2.500 €$ & $\mathbf{2 , 2}$ \\
\hline $2.501-3.000 €$ & $\mathbf{1 , 2}$ \\
\hline Over $3.001 €$ & $\mathbf{1 , 4}$ \\
\hline N/A & $\mathbf{3 8 , 5}$ \\
\hline
\end{tabular}

Source: GPO \& KEADIK 2013: 24.

Moreover Greek NEETS compared with the rest of their peers live in homes in which a) inhabit more and b) work fewer household members (see GPO \& KEADIK 2012: 22 and GPO \& KEADIK 2013: 19 and Chart 5) which aggravate their already financially troubled families and by extension themselves. It is worth noting that the NEETS:

a) have lost their father at a rate of $8 \%$ compared to $4.1 \%$ of the total

b) have lost their mother at a rate of $2.3 \%$ vs. $1.1 \%$ of the total (see GPO \& KEADIK 2013: 24).

Chart 5: Family Situation in which Neets reside.

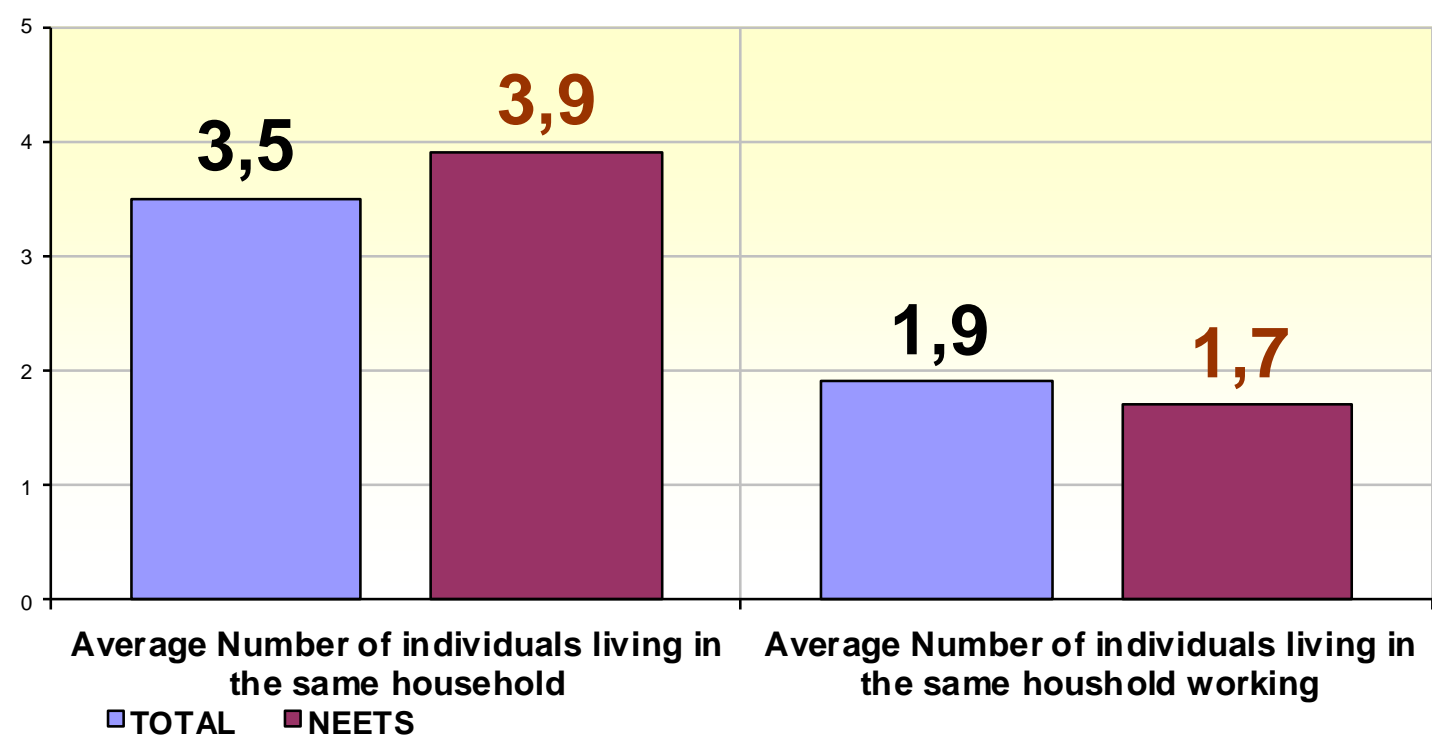

Source: GPO \& KEADIK 2012: 23 
- It is obvious that the inclusion in the category Neet is directly correlated (more precisely: determined by) with the family income. Most simply as smaller is the monthly family income the greater the chances for a new person to come into the category of Neet. Despite the limited assets of their families, the vast majority of Neets are supported by them. The fact that almost all of the Neets are single definitely plays an important role to their attachment with the family environment. $87.2 \%$ of Neets are staying with their families (only a percentage not exceeding $10 \%$ are living by themselves or together with a friendly person - see. GPO \& KEADIK 13: 14), while the families of Neets are usually more large than the families of the rest of the population to which they belong (see in detail GPO \& KEADIK 2013: 19). The absolute dependence by the family (see also Kotrogiannos et al 2013: 194) is also supported by the fact that only $4.5 \%$ of Neets receive some kind of benefit, while for the $85 \%$ of Neets [also here, there is an absolute convergence between the first and second phases' quantitative research findings, as the figure for the first phase was 83\% (see GPO \& KEADIK 2012: 36)], family is the only source of income support (see GPO \& KEADIK 2013: 24 and Pandis \& Zagos 2013: 116). However it should not be ignored the percentage of Neets (reaching 7, 5\% - GPO \& KEADIK 2013: 24) that has no financial support. These individuals are more likely to be isolated completely and be found in the margins of Greek society and certainly for these Neets immediate and targeted intervention is needed. In essence they constitute a subcategory of major social vulnerability. The correlation of economic capital and inclusion in the category of Neets confirms the case of poverty's intergenerational transmission in Greece (Papatheodorou \& Papanastasiou, 2010). This case is reinforced by the finding (see in detail \& KEADIK KANEP 2012: 56-57) that, in relation to the whole, parents of NEETs have lower educational attainment, while usually fewer members of their families work compared to the overall condition of the corresponding population having the same age (see Chart 5). It is also worth noting that the educational level of parents is, primarily, that of secondary education while those attained higher education are less (very few are those who are primary school graduates - GPO \& KEADIK 2012: 56). In relation to the whole, parents of NEETS have markedly lower educational attainment (see GPO \& KEADIK 2012: 25), "which raises the question of the correlation between deficits in educational-cultural capital and socio-educational inequalities, also based on Pierre Bourdieu's theory of cultural osmosis"(see in detail, Bourdieu 2002; Drakaki et al. 2013: 228). At this point we must return to family's pivotal role. The aforementioned findings and conclusions indicate a low degree of autonomy enjoyed by young people in Greece today. This fact - i.e. the lack of autonomy - prevents the all-round development of young people's personality and their smooth integration not only in production but also in the social net. On the other hand, family seems to be the only effective support structure that they have. However strong links developed between members of families in Greece, many times hamper young people's individual decisions and choices and consequently the creation of new life routes or the simultaneous coevolution of different routes. The overprotectiveness usually inherent in Greek 
family institution may form a NEET's mentally weak personality or potentially, without a will, cut off from the rest of society, passive, without appetite for initiatives. For NEETs, in both cases, family works both supportingly by providing financial and psychological care and also aggravatingly/deterrently by providing many tangible and intangible goods (money, food, shelter, psychological support) possibly leading indirectly NEETs or the potential NEET in passivity, abdication of any effort, marginalization and ultimately in their social and labor exclusion. On the other hand it should be pointed out that the family seems to be the most protective grid, de facto replacing the welfare State and its services that basically ignore Neets (of course, on their part, NEETs themselves not unjustly treat welfare State with great caution, as we will later see in detail).

- The vast majority of Neets $(66.2 \%$ in the second phase of quantitative research with little deviation from the first $-69.3 \%$, see in detail GPO \& KEADIK 2012: 59 and GPO \& KEADIK 2013: 20) has worked in the past, mainly in the tertiary sector. Some $26.2 \%$ of Neets is found in long-term unemployment (GPO \& KEADIK 2012: $31)$.

Chart 6: Previous work experience of Neets (with regard to the Neets who have worked in the past).

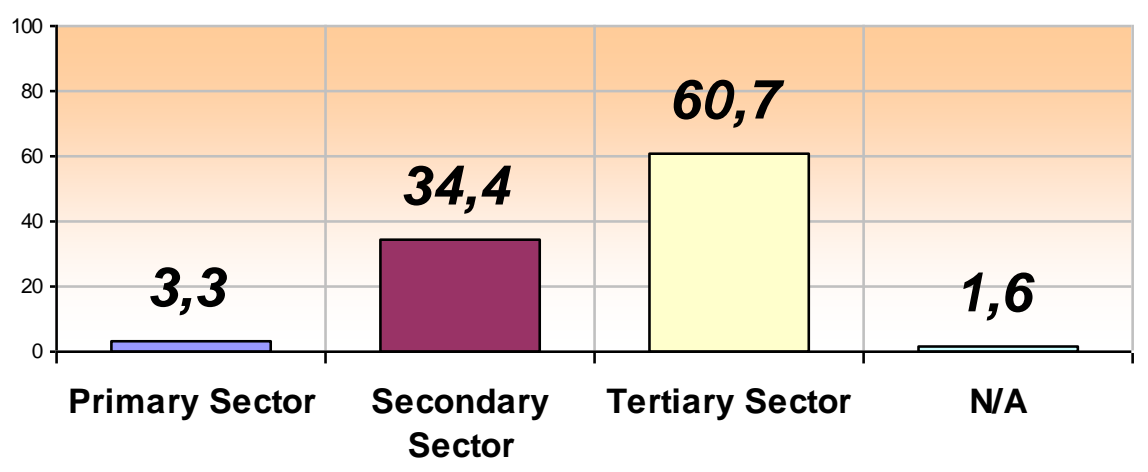

Source: GPO \& KEADIK 2012:29.

Therefore, Neets usually have previous work experience, but one that is largely seasonal-casual employment, mainly for a period of time less than 1 year or even six months, which is confirmed by the quantitative and qualitative research (see GPO \& KEADIK 2013: 49, Drakaki et al. 2013: 229, Pandis and Zagkos 2013: 114-115 and Kotrogiannos et al. 13: 188). They mainly have worked in catering, leisure and tourism. From the group of Neets with prior work experience, the majority are men 20-24 years old. Several Neets though (30.7\%) have not even entered the labor market, while there are several long-term 
unemployed at older ages $(32.6 \%$ of Neets total who had worked in the past-see GPO \& KEADIK 2013: 20). Delaying entry into the labour market decisively hampers the possibility of integration into employment in general. Regarding the employment situation and broadly the relationship of NEETS to employment, it is clear from the findings that the economic crisis has contributed decisively to their unemployment, as grosso modo two main categories of Neets have been formulated: those who have not worked at all and those who worked for a while and have been laid-off either because of cutbacks in personnel, either due to bankruptcy of the company that were employed, or because they were seasonal or occasional workers. Of course, it should not also be ignored the case of those Neets who left voluntarily. Very characteristic here are the findings of qualitative research (see in detail KANEP \& KEADIK 2013: 17). One in five Neets-respondents reported that resigned for various personal reasons (these include conflicts with their managers, with their superiors, delays in payment and dissatisfaction with the working conditions - see also Kotrogiannos et al. 2013: 188). Summing up, it can be observed that the working environment in general is not conducive to the formulation of those circumstances which will contribute to the creation of stable and adequate working conditions. Indeed, it is a parameter that is also strongly emphasized in interviews, in which the lack of employment opportunities both in public and in private sector is also highlighted. But how do NEETs searching for a job? In fact, in 3 ways: through acquaintances, through advertisements and through Manpower Employment Organization OAED (see Kotrogiannos et al. 2013: 189). According to the qualitative research, it is very interesting that through the mediating structures of the Manpower Employment Organization, just one in ten respondents searches for occupational rehabilitation; something "that clearly shows the lack of confidence in the public employment agency structures" (KEADIK \& KANEP 2013: 18).

- The minority of Neets have attended some training program and from them, the vast majority considers training ineffective. It is obvious that despite unemployment, Neets don't trust training. Some $75 \%$ of Neets has never followed a training program, and in many prefectures this percentage exceeds $90 \%$ (see in detail GPO \& KEADIK 2012: 32). The training programs were more attended by women, members of the 20-24 years old age group and the residents of urban areas. Those Neets that have previously been trained declare (and this is quite evident in the qualitative research-see in detail KEADIK \& KANEP 2013: 23 and Kotrogiannos et al. 2013: 187) that training did not help them at all in vocational rehabilitation (see also Drakaki et al. 13: 229 and Chart 7) i.e. it did not work as a proactive employment policy, although this is its fundamental function. 


\section{Macrothink}

Chart 7: Evaluation of training's effectiveness by the Neets (if it helped them finding a job - with regard to the Neets who have attended a training program).

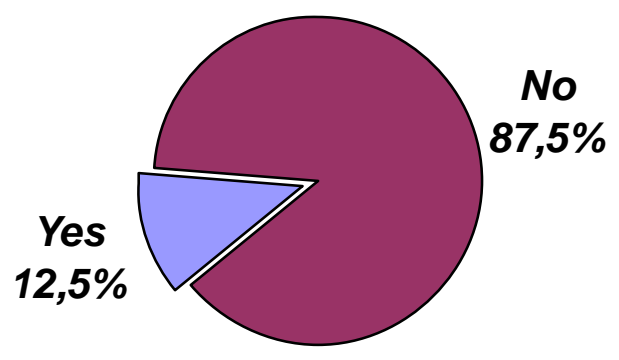

Source: GPO \& KEADIK 2012: 31.

- Despite their apparent disbelief in training programs, a large proportion of Neets (56.8\%) would like to attend a training program again, mainly in order to increase the chances of finding a job, and secondarily to enrich their knowledge. Women appear much more positive in such a perspective at a rate of $70 \%$ versus a $39.5 \%$ of men (see in detail GPO \& KEADIK 2012: 32). For young people aged between 20 to 24 years old training programs are mainly related to the possibility of finding a job (76.1\% of Neets is in the process of finding jobs, a percentage that climbs up to $86.4 \%$ for Neets aged 20-24 years old-see GPO \& KEADIK 2012: 35) while for the younger, aged 16 to 19 years old, training programs are a chance to enrich their knowledge. Initially this finding seems contradictory: Neets want to engage in a process that they do not trust. But is that the case? It is interesting to note that, as is demonstrated both by the quantitative and qualitative research, Neets feel trapped as they see employment opportunities not been provided by either the public or the private sector (see KANEP \& KEADIK 2013: 18 and Kotrogiannos et al. 13: 190-191); and inevitably seek a "tool" for their potential reintegration. This is very difficult in a country with deficient Lifelong Learning culture and with training that is not job related and not targeted (i.e. based on needs assessment). According to Eurostat 2009 Greece, out of a 27 countries total, occupied the penultimate position in adult participation in lifelong learning $(3.3, \%)$ while the EU-27 average was 9.2\% (see Eurostat (LFS) as cited in European Commission, 2013: 68). The data showing the comparative development of lifelong learning in Greece with the EU average from 2000 to 2010 are of particular interest. Specifically when in 2000 that percentage was $2.6 \%$ for Greece, the EU average was 8.5\% ; respectively in 2008 was $2.9 \%$ with the EU Average been $9.5 \%$ and in 2012 was $2.9 \%$ versus $9 \%$ of the EU average (Papadakis 2012 and in detail Eurostat (LFS) as cited the European Commission, 2013: 68). It is important that the EU has invested particularly in the issue of lifelong learning: the target of the Lisbon strategy for 2010 was $12.5 \%$ while the EU2020 target for 2020 is 15\% (see European Commission 2009: 14, Kalerante et al., 2009 and Papadakis, 2013b). This is a policy domain where Greece seems to lag decisively, also exacerbating among other the deadlocked of Neets (who, let's not forget, have as a second priority, after finding a job, the return to 
some form of systematic learning process).

- The majority of Neets who have left school early (few in total), has done it mainly for economic reasons $(42.9 \%)$, and that is confirmed by both quantitative and qualitative research (see GPO \& KEADIK 2012: 33, KEADIK \& KANEP 2013: 35-36, Kotrogiannos et al 2013: 182). This fact confirms the Sociology of Education hypothesis for the association of economic inequalities with school dropout (Kyridis, 1998, Kyridis et al. 2011a). Also the other reasons which led to early school leaving (family and personal) array with the classic causes of dropouts. It appears that the de-standardization of the biotic tracks and the biographical trajectories of individuals as well as the biographical models that also often predetermine women's life cycle (school - work - marriage - a family - birth of offspring) govern to a great extent the personal choices of NEETs. The de-standardization of young people's various biographical trajectories is nowadays expressed by the time displacement of their life activities, which were specified to occur at specific time life periods and age stages and which interlock with each other, and ultimately may be realized at other times and age periods or even follow a parallel course (see Tsiolis, 2006: 125). This is a phenomenon which predominantly relates to Neets. The occurrence of an event (in qualitative research we have examples of early pregnancy, drugs, expulsion from the family home-see KEADIK \& KANEP 2013: 44) may have led or will lead NEETs to choices that cause "biographical ruptures" in their life cycle, resulting in been absent from education, training and employment (see in detail Tsiolis, 2006: 124-126). Of course the main biographical rupture for Neets is the "advent" in the state of unemployment. Also, according to the analysis of the aforementioned research's qualitative data (see KANEP \& KEADIK 13: 12), Neets appear highly pessimistic regarding the return opportunities in the education system. Especially in qualitative research the majority of respondents answer that the educational system in Greece gives little to no opportunities to people who have dropped out to return to the educational process, despite the desire of several of them to come back (see also Kotrogiannos et al. 13: 123). In a country with a tradition of centralization, absence of institutional framework recognizing informal and non-formal learning and with a deficient lifelong learning network (which is what typically provides alternative learning paths), Neets seem to have been right in their valuation. Therefore, the need for a substantial reform of the educational system and for increasing its attractiveness and effectiveness is reinforced. Essentially, the vast majority of NEETs considers education completely ineffective with respect to its connection with the labor market (and indeed this view permeates Neets regardless their educational level-see Drakakis et al. 2013: 229), something that is not far from the Greek educational reality (see KANEP / GSEE 2013:11, Kotrogiannos et al 2013: 187, 124 \& 125 and Kyridis et al 2011b: 1-19). This view is reinforced by the fact that almost all of the respondents state that if they were called to be trained with the assurance that they will find a job, they would have participated (see in detail KEADIK \& KANEP 2013: 14 and Kotrogiannos et al. 2013: 127). Additionally several NEETs request a change/reform for the education system, which is often characterize "inadequate", in the direction of 


\section{Macrothink}

the connection with the needs of the labor market, and of greater flexibility and effective learning (see KANEP \& KEADIK 2013: 12 and Kotrogiannos et al. 13: 186). However, as has already been pointed out, the narrow majority of Neets declares its intention to return to education (see chart 11), with the corresponding percentages reaching $75 \%$ for men and $60 \%$ for young people aged between 20 to 24 years old. Economic distress acts deterrently to such reintegration (KEA $\triangle I K$ \& KANEП 2013:

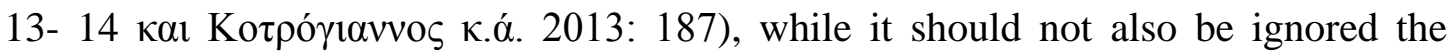
parameter of the lack of interest from NEETs' part. The latter highlights the educational system's lack of attractiveness and motivation and requires a completely different, from the existing, lifelong learning strategy, as well as a new culture (in the form of integrated network) in providing educational "second chances".

\section{Chart 8: Early dropout NEETS' desire to return to the educational system}

Source: GPO \& KEADIK 2012: 33.

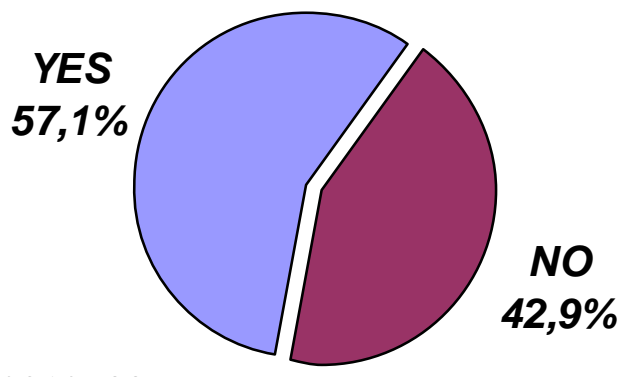

- It is also impressive the fact that while the vast majority of Neets (76.1\% in total, a percentage that climbs up to $83.3 \%$ in the ages $20-24$ years old-see GPO \& KEADIK 2012: 35 ) is in the process of finding jobs (see Figure 9 for the priorities of Neets), much fewer address State employment structures, in specific $30.7 \%$ according to the quantitative research (see GPO \& KEADIK 2012: 35) and even fewer according to the qualitative research (see above). Their mistrust towards the State structures is obvious, and that is also confirmed by other research findings (see Chart 10). 


\section{Al Macrothink

\section{Chart 9: The priorities of Neets}

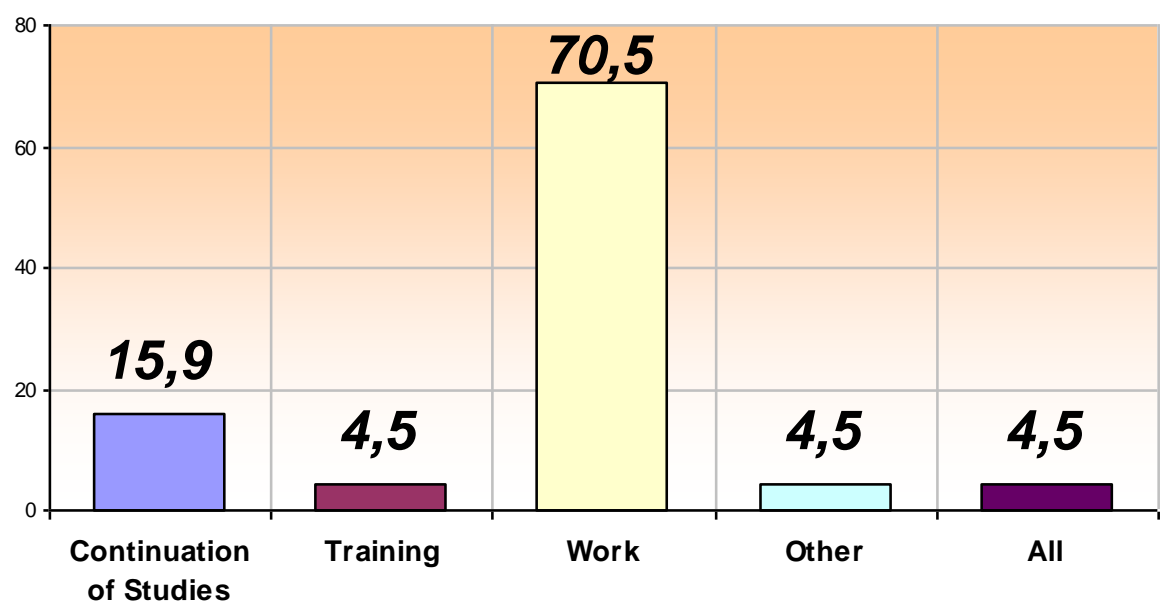

Source: GPO \& KEADIK 2012: 41.

Chart 10: Confidence of Neets in the structures of the welfare State (Question: do you trust the Greek State regarding civil protection structures - social benefits etc?)

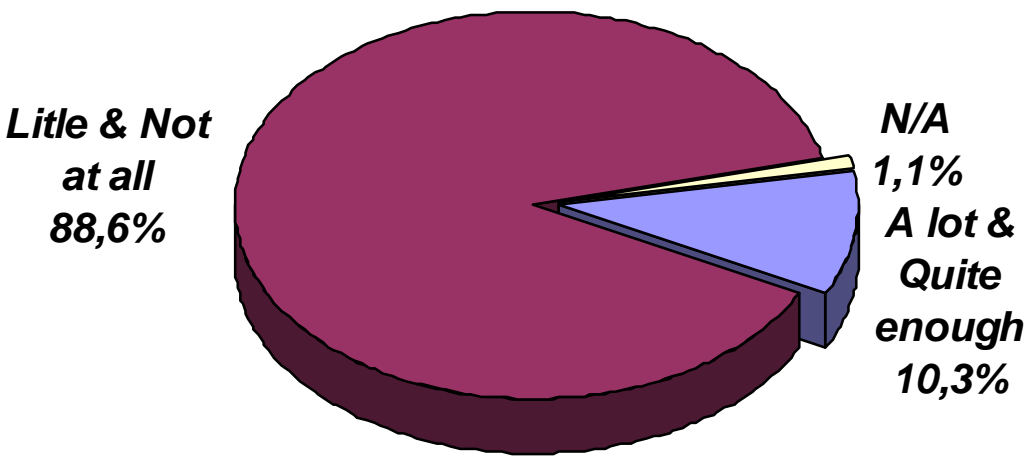

Source: GPO \& KEADIK 2012: 35.

- Only a very small percentage (4.5\% - see GPO \& KEADIK 2012: 36) relies financially on the unemployment allowance. Youth unemployment, low wages, the mismatch between studies and specializations demanded, flexible and "black labor", constitute a painful environment in within which young people are forced to move. On the individual level, the social and psychological implications are enormous, since the agony of a decent vocational rehabilitation is transformed into a purely "personal and family" issue, and for which the State is not taking its share of responsibility. However, the internalization of professional deadlock as an only personal failure and 
not as an educational and social dysfunction constitutes a painful experience that can lead to frustration and the generalization of insecurity with the cancelation of personal dreams, the feeling of low self-esteem, and in extreme cases to nihilism and the depreciation of social goods (see Panagiotopoulos, 2005).

Table 4: Problems in the labor market in the EU countries and the OECD countries' averages

\begin{tabular}{|l|l|l|l|l|}
\hline & $\begin{array}{l}\text { Difficulty in } \\
\text { recruitments } \\
\text { (index 1 to } \\
100)\end{array}$ & $\begin{array}{l}\text { Rigidity in } \\
\text { working hours } \\
\text { (index 1-100) }\end{array}$ & $\begin{array}{l}\text { Difficulty in } \\
\text { dismissals } \\
\text { (index 1-100) }\end{array}$ & $\begin{array}{l}\text { Rigidity of } \\
\text { the rabor } \\
\text { market (index } \\
1-100)\end{array}$ \\
\hline Greece & 44 & 67 & 40 & 50 \\
\hline Denmark & 0 & 20 & 0 & 7 \\
\hline Germany & 33 & 53 & 40 & 42 \\
\hline Ireland & 11 & 0 & 20 & 0 \\
\hline OECD Countries & 26,5 & 30,1 & 22,6 & 26,4 \\
\hline
\end{tabular}

Source: "Regulations in Employment" ECS 2009, Doing Business Report 2009-2010, World Bank, as cited in Kalerante et al., 2009.

- It becomes apparent that Neets need an effective welfare state (as at a rate of $96.6 \%$ they assume that the protection of socially vulnerable groups is conditio sine qua non for a civilized society and also the responsibility of the Welfare State-see GPO \& KEADIK 2012: 45), which they designate as a critical tool to mitigate social inequalities (indeed, at a rate of $80.7 \%$, they directly relate the existence and effective functioning of the Welfare State to the alleviation social inequalities). Some 96,6\% of Neets considers that the role of the welfare State is to protect all citizens regardless of cost (see in detail GPO \& KEADIK 2012: 45). Neets, in addition, consider that cutbacks in the welfare State and its gradual weakening bear great responsibility for the situation in which they have fallen, while at the same time all these played a role in the widening of social inequalities. Simultaneously, they estimate $(68.2 \%)$ that the irrationalism in the functioning of the Welfare State and the State in general in addition to the wider "reckless benefits" have led the country to the current impasse, from which they themselves are primarily affected (see GPO \& KEADIK 2012: 48). Indeed a $78,4 \%$ of Neets is afraid that now has lost an important opportunity as the 
containment of costs has led to "social expenditure no (longer) be feasible by the State" (see GPO \& KEADIK 2012: 46). They insist, however, that even in these tough economic times the last a State should do is cut the social benefits from those who really need them. In short Neets believe in the importance of an organized and efficient welfare state, however, strongly criticize the existing Greek Welfare State. The distrust extends more to the State in general and its structures (see Kotrogiannos et al. and 2013: 198). Something that becomes particularly evident in the qualitative research is that the Neets not only do not trust the State and the political system, but even more so they consider the State, the existing public policies and governmental choices as primarily responsible for the difficult situation in which they are (see KEADIK \& KANEP 2013: 24 and Kotrogiannos et al. 13: 193). They even go further in making specific recommendations which are mainly related to the emphasis on growth and to attracting investments to create new jobs (KEADIK \& KANEP 2013: 24). The Greek NEETs believe that a restructure of the labor market needs to take place together with radical changes and restructuring across the range of State structures (programs for unemployed workers, systematic evaluation and training programs such as seminars, etc.), as well as serious transformations in the political system, changes in Greece's civilian staff and the strengthening of the welfare State (see KANEP \& KEADIK 2013: 24 and Kotrogiannos etc. in 2013: 193 \& 198). In essence they are seeking a new productive model. Striking is the fact that despite the difficult situation, Neets in their majority do not want the benefits exclusively for the indigenous groups (see GPO \& KEADIK 2012: 44 \& 46). In a field of social vulnerability, where xenophobic syndromes could be developed, Neets appear savvy and in solidarity to social groups of diverse ethnocultural origin.

- A seemingly paradoxical finding is related to whether Neets, a most socially vulnerable group, unemployed and cut off from institutions and the considerations of the welfare State, feel socially excluded: and yet Neets do not feel socially excluded at a rate of $84.1 \%$ (see GPO \& KEADIK 2012: 39), which is strongly evident from both the qualitative and quantitative research (see GPO \& KEADIK 2012: 39 KEADIK \& KANEP 2013: 28 Kotrogiannos et al 2013: 196 and Drakaki et al 2013: 232). But is this finding interpretable? Undoubtedly Neets qualify for classification as socially excluded. However as already stated they do not feel so themselves. The family security grid (70.5\% find not only economic but also psychological support within their family-see GPO \& KEADIK 2012: 39), groups of similars, the widening of social vulnerability that inevitably brings many young people in a similar situation with Neets, reduce the feeling of alienation and isolation. Many of NEETs stand on the fact that they have friends and companions (social protection grid) on which they rely and thereby feel that participate actively in society (see KEADIK \& KANEP 2013:28 and Kotrogiannos et al. 2013: 196). From the above it appears that the lack of the sense of exclusion felt by NEETs is due greatly to the sense of collectivity and solidarity they feel between them. In other words, that they are not on their own and there are others like them. The painful changes and upheavals brought about by the economic downturn in Greece's social and economic scene and the deterioration of 
NEETs living standards and therefore the pausing, the change of direction or the dissolution of the their lives cycle, had as an inevitable result the partial or total disruption of NEETs' value system and of their identity coherence (see more detail about these issues see Hall, 1992/2003: 401 as cited in Tsiolis, 2006: 126). The disruption of their biotic trajectory, which was established by the various biographical embodiments of Greek society (social rules, norms, standards of biographical character) as well as by personal choices and events (see Fischer \& Kohli, 1987: 28 as cited in Tsiolis, 2006: 125) and the start of a new biotic path under adverse conditions, leads NEETs towards to a search of their identity as a subject and as part of the society in which they live (Passerini, 1998: 21-38 as cited in Tsiolis, 2006: 126). The similarity of their own biographical routes with those of their peers contributes greatly to NEETs' biographical reconsideration for the (re) construction of their "self" identity (see Tsiolis, 2006: 127) and in understanding him/herself and his/her existence as a person and as a whole in Greek society. Going out and discussing with people who belong to the same category of social vulnerability as the NEET does, passes to another level of meaning and interpretation. The dialogue among NEETs or similar socially vulnerable groups and the exchange of views, experiences and the storytelling of events and incidents on how one comes to that state contributes, in a personalized manner now, in the creation of a continuous and coherent form of events that have been instrumental in one becoming a NEET (for personalization process see also Tsiolis 2006: 122-128), and allows you to redefine and to protect your identity, but also to develop exit strategies. The understanding and awareness of the key choices made by NEETs and the significant effect of exogenous factors (political, economic, institutional, etc.) and of their social environment, contribute to NEETs' interpretation of the interaction that exists between their social exclusion and the various stages of their life cycle (see in detail about these issues Linde, 1993 as cited in Tsiolis 2006: 127). It cannot however be ignored a $28.4 \%$ which indicates that it has no such support from anywhere. At the same time $15.9 \%$ of Neets say they are socially excluded and even more in the absolute degree (see in detail GPO \& KEADIK 2012: 39). They have completely crossed the "threshold of suffering". It is the most burdened subcategory of Neets.

- The majority of Neets is insured $(72,1 \%)$ mainly through their parents' insurance carrier. However not negligible is the percentage of Neets who are uninsured (26.8\%) (see GPO \& KEADIK 2013: 22). It is especially so if we take into account the high percentage of Neets $(51,2 \%)$ stated that are uninsured in the context of qualitative research (see Kotrogiannos et al 2013: 190). The lack of insurance coupled with unemployment exacerbates the condition of insecurity and uncertainty.

- The economic situation of Neets is particularly difficult, as indeed one would expect, a finding confirmed by both from the quantitative (see. GPO \& KEADIK 2012) as well as qualitative research (see KANEP \& KEADIK 2013: 31 and Kotrogiannos et al. 2013: 193). As already noted, the basic and usually the only alternative source of income for their support is family (as discussed earlier in this chapter, a Neet usually 
has very limited incomes).

- Neets do not neglect their health. $82.9 \%$ of Greek Neets takes care of his/her health, with $36.4 \%$ believing that it is in excellent condition, $49.9 \%$ in good and $11.6 \%$ in a moderate level (see Chart 11).

\section{Chart 11: Neets' valuation of their health level}

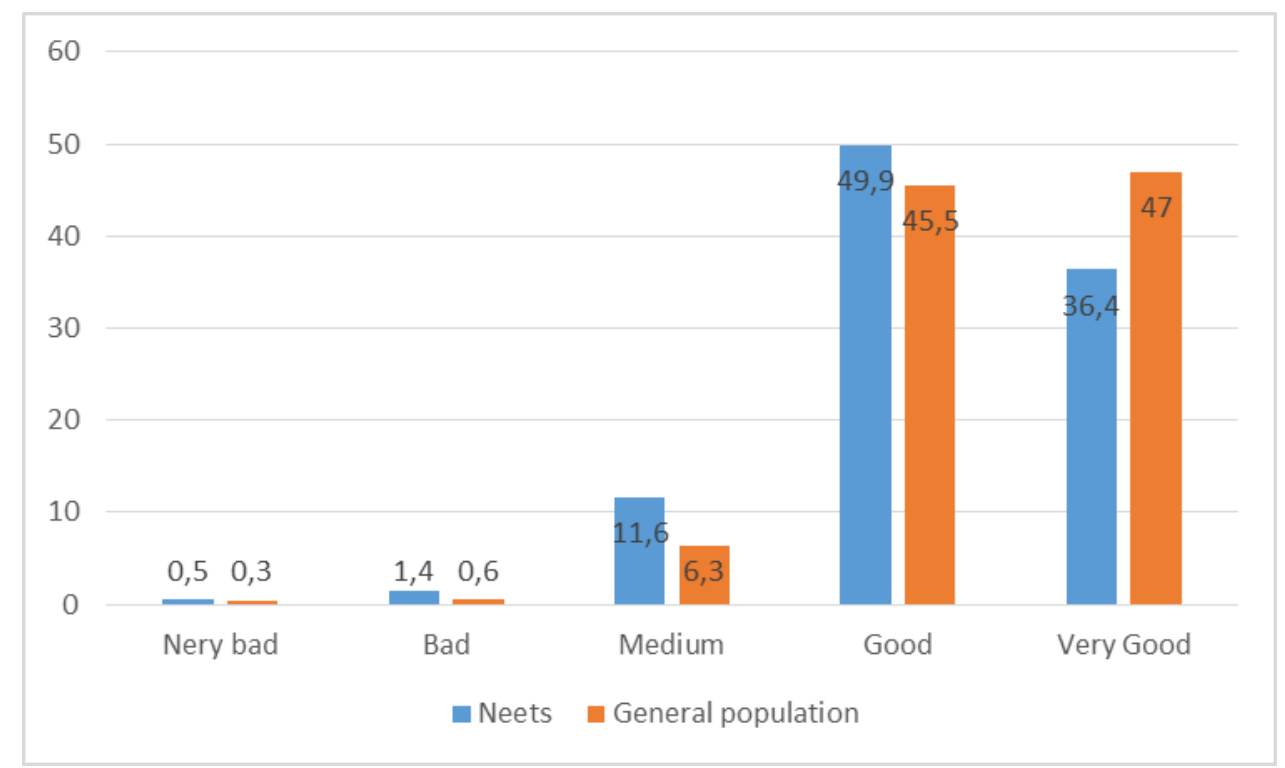

Neets Mean: 4,21 General Population: 4,39

Source: GPO \& KEADIK 2013: 14

It is noteworthy that the percentage of Neets who consider their health level bad and very bad is minuscule (within the limits of statistical error). Some $42 \%$ of women versus $28.9 \%$ of males and $39.4 \%$ of young people aged $20-24$ years old vs. $27.3 \%$ of young people aged 16-19 years old characterize their level of health as excellent (see GPO \& KEADIK 2012: 50). However despite the care for their physical health and its good condition, a great problem arises in relation to mental health: stress is part of everyday life for $54.6 \%$ of Neets in a large or quite large degree, mainly for the $66 \%$ of women and the $59.1 \%$ of those aged 20-24 years old who are experiencing job insecurity in a more intense degree (see GPO \& KEADIK 2012: 38 \& 67). The findings of the quantitative research for this aspect of Neets' situation are also fully confirmed by the qualitative research (see KANEP \& KEADIK 2013: 26). Qualitative research has furthermore highlighted another aspect, namely the feeling of despair (a situation faced by 31,7\% of respondents-see KEADIK \& KANEP 2012: 26-27 and Kotrogiannos et al. 13: 195). 


\section{Macrothink}

- Neets, as already noted, consider as pivotal the role of the Welfare State in reversing the situation in which they have fallen into. But they are absolutely frustrated both by the operation of the welfare State, as well as by the State in general, its structures, the civilian personnel and the political parties. The frustration by the inefficiency of the Greek welfare state (GPO \& KEADIK 2013: 42) and generally by the Greek political system (see KEADIK \& KANEP 2013: 29 and Drakakis et al 2013: 231) is also obvious in NEETs' confidence indicators which show that they hardly trust anyone else other than their family and those closest to them, e.g. friends; and this is combined with the personal disappointment, due to the situation in which they are found. Here we should note that the insecurity and uncertainty that has breached the frame of their biography's co-articulation (framework of standard biography - see in more detail on this issue Alheit \& Bergamini 1998: 122), meets the deadlock in Neets cases who feel strongly the emotion of frustration (and, as we have seen, not a small portion of them).

- Skeptical towards the educational system and training structures, frustrated by the operation and effectiveness of the welfare state, in a difficult financial position, been in an (unsuccessful) job search, trapped in daily stress and relying almost exclusively on family, Neets do not cease to have goals for the future $(94.3 \%$ - see GPO \& KEADIK 2012: 40) and to (re) designing their biotic trajectory (life-course). These goals are associated primarily with the integration into the labor market and secondly with some form of reintegration into the educational process. At this point it should also be noted that unemployment is the most important factor, as it emerges from the qualitative interviews, bringing adverse effects to NEETs (see KANEP \& KEADIK 2013: 24). Most NEETs consider that above all they must find work in order to survive. It is noteworthy that the majority of Neets maintains optimism for achieving these goals. However it cannot be ignored a 40,9\% who considers that these objectives are rather difficult or even impossible to achieve (see GPO \& KEADIK 2012: 51). The combination of social vulnerability and pessimism leads directly to the withdrawal, an extremely dangerous phenomenon. In essence the percentage of the "pessimists" confirms the "vicious circle of poverty" (see in detail Pyrgiotakis, 1998).

- In each case a particularly high proportion of Neets directly links the strategy of achieving goals with mobility. To achieve their objectives the majority of NEETS is prepared to move to another region of Greece, while even higher is the proportion of those who are thinking of migrating abroad. Specifically in order to achieve their goals, $44.3 \%$ of Neets is prepared to move to another region of Greece, while even larger $(56.8 \%)$ is the percentage of young people who are thinking of migration abroad. More positive on the prospect of internal migration are women at a rate of $56 \%$, while on the other hand men and residents of rural areas think more of possibly migrating abroad at rates 65.8\% and 64.6\% (see GPO \& KEADIK 2012: 40 \& 69). The intention of migrating abroad is even more evident in higher education graduates, as we have already pointed out (see detail KEADIK \& KANEP 2013: 38-39 and Kotrogiannos et al. 2013: 194). Therefore, young people's tendency of migrating is 
confirmed, which among other things has already contributed to a painful brain drain.

To ensure and protect their identity in conjunction with an understanding of the "Self" and the realization of the social reality through their family and social network, directs NEETs in taking measures to tackle their social vulnerability. Both the continuation of the effort to look for employment, together with their willingness of migrating abroad, it now makes their occupational route their top priority in their new cycle of life. It is literally a hierarchical path of life, especially when referring to young people who have suffered a crucial biographical rupture (they are "absents").

Based on the aforementioned, it is established that the difficult economic and social situation, suffered by NEETs in Greece, the deterioration of their living standards and the daily and continuous problems that they face are not due to personal behaviors or choices but mainly stem from the dysfunctional and "hidden" Welfare State, the disassociation of education and training from the labor market, and the impact of the economic recession to the employment situation in general.

But what do the Neets suggest in order to change the state of things?

The proposals of Neets summarize in 3 levels (see in detail KANEP \&KEADIK 2013:21 and Kotrogiannos et al. 13: 186, 192, 193):

- Structural and organizational changes in the labor market.

- Changes in the structure and services of the welfare State, in order, on the one hand, to strengthen and secondly to focus more and more effectively on social vulnerable groups. Special emphasis is given to the creation of efficient employment finding structures and to the reform of the educational system (as we have already pointed out). Moreover, we must not forget that a key challenge for the NEETS is finding a job at a rate of $70.5 \%$ and the reintegration into the educational process (15.9\%) (see GPO \& KEADIK 2012: 51).

- Transformations in the political system and changes to the civilian staff in the direction of strengthening transparency and meritocracy, to fight corruption and to rationalize the functioning of the State and public administration. 


\section{Conclusion}

Neets, in Greece show a remarkable heterogeneity. However the analysis of characteristics and trends enable us to sketch out, with relative safety, the main parameters of the phenomenon.

Thus, the Greek Neet (whose profile has been described in detail in Drakakis, Papadakis, Kyridis \& Papargyris, 2013) belongs more often in the 20-24 years old age category, can be male or female (most often female), has a fortiori Greek citizenship, mainly has medium educational level (but also is not negligible the proportion of tertiary education graduates), often has prior work experience, comes from a family with low (primarily) income, while he or she (the great majority) has not attained a training program. He or she is supported by his family, is often uninsured and feels socially excluded; is absolutely skeptical towards the social State, expresses intense discomfort for the political personnel and delegitimizes the political system. At the same time he/she is also skeptical as to the functioning and opportunities of the realm (education-training-employment) from which is absent (primarily not by personal desire). Despite the multiple parameters of inconvenience, the aforementioned frustration, and given that stress is part of his/her everyday reality, he/she sets goals and develops exit strategies from the difficult situation in which he/she has fallen. NEETs are not always optimistic that they will succeed, however pose as key priorities the (re)integration to the labor market and secondly a return to some form of learning process. The biographical rupture which a NEET has suffered and the vulnerability which he/she undergoes do not prevent him/her from redrawing his/her life orbit and from highlighting broader proposals to address social vulnerability and mitigate social inequalities.

The percentage of Neets, as demonstrated by the findings of the survey "Barometer of Absents", is particularly high in Greece. The quantitative mapping of NEETs based also on specific demographic characteristics, as well as the recording of the qualitative characteristics of an undoubtedly multi-parametric phenomenon are leading to the conclusion that in Greece is required a combined, multi-layered and targeted intervention that can re-integrate Neets. The systematic utilization of the "Barometer of Absents" research findings and also the development of an empirically based policy mix (see Fotopoulos 2013) constitute an urgent need both in national and in regional level.

\section{Bibliography}

Alheit, P. \& Bergamini, S. (1998). Biographical research and life history research, in S. Papaioannou (ed.), Social Transformation, Education and Local Community, Rethymnon: University of Crete - International Postgraduate Summer School, 1998, pp. 122-130 (in Greek).

AUDIT COMMISSION, (2010). Against the odds: Re-engaging young people in education, employment or training. London: Audit Commission.

Bell, D. and Blanchflower, D. (2010). Youth Unemployment: Déjà vu? Bonn: Institute for the 
Study of Labour.

Bourdieu, P. (2002). The Distinction. A social critique of the judjement of taste. Cambridge: Harvard University Press.

Breen, R. (2005). Explaining Cross-National Variation in Youth Unemployment. Market and Institutional Factors. European Sociological Review, 21(2), 125-134.

Bynner, J. and Parsons, S. (2002). Social exclusion and the transition from school to work: the case of young people not in employment education or training (NEET). Journal of Vocational Behaviour, 60, 289-309.

Centre For the Development of Educational Policy (KANEP/ GSEE), (2013). The basic figures of education. The Greek Higher Education. Part A', Athens: KANEP/ GSEE (in Greek).

Coles, B. (1995). Youth and Social Policy. London: UCL Press.

Drakaki, M., Papadakis, N. Kyridis, A. and Papargyris, A., (2013). The NEET's profile in Greece, in N. Papadakis (ed.), Absents' Barometer: The NEETs (Young People Not in Education, Employment or Training) in Greece (in Greek). Athens: Sideris, pp 209- 240 (in Greek).

EUROFOUND, (2012). NEETs - Young people not in employment, education or training: Characteristics, costs and policy responses in Europe. Luxembourg: Publications Office of the European Union.

EUROPEAN COMMISSION, (2009). Progress Towards the Lisbon objectives in Education \& Training. Indicators \& benchmarks. Brussels: EC DG EAC (SEC (2009)1616. Brussels: E.C. 2009.

EUROPEAN COMMISSION, (2011). Youth neither in employment nor education and training (NEET). Presentation of data for the 27 Member States. EMCO Contribution, European Commission/ DG Employment, Social Affairs and Inclusion. Available online at: http://ec.europa.eu/social/keyDocuments.jsp?type=5\&policyArea=81\&subCategory $=115 \&$ co

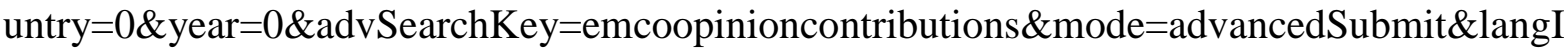
$\mathrm{d}=\mathrm{en}$.

EUROPEAN COMMISSION, (2012). Commission Staff Working Document. Vocational Education and training for better skills, growth and jobs. Accompanying the document Communication from the Commission "Rethinking education: investing in skills for better socio-economic outcomes. Strasbourg: E.C., SWD(2012) 375 final. Available online at: http://ec.europa.eu/education/news/rethinking/sw375_en.pdf.

EUROPEAN COMMISSION, (2013). Education and Training Monitor 2013. Brussels: E.C. DG EAC. Available online at: http://ec.europa.eu/education/documents/eatm/education-and-training-monitor-2013_en.pdf

EUROSTAT, (2012). Europe in figures. Eurostat Yearbook 2012. Luxembourg: Publications 
Office of the European Union, 2012. Available online at http://epp.eurostat.ec.europa.eu/cache/ITY_OFFPUB/KS-CD-12-001/EN/KS-CD-12-001-EN .PDF

EUROSTAT, (2013). Euro Indicators. Euro area unemployment, Eurostat News Release, Vol. 102, 2 July 2013.

Fotopoulos, N. (2010). The phenomenon that is sweeping in Greece, Europe. The outcasts of Education - Student leakage and early school leaving in Greece and Europe, The Eleftherotypia, 16.2.2010. Available at: http://www.enet.gr/?i=news.el.article\&id=132384

Fotopoulos, N. (2013). The problem of Neets and the Greek reality. Seeking solutions to Greece's Memorandum, in N. Papadakis (ed.), Absents' Barometer: The NEETs (Young People Not in Education, Employment or Training) in Greece (in Greek). Athens: Sideris

Furlong, A. (2006). Not a very NEET solution: representing problematic labour market transitions among early school-leavers. Work, Employment and Society, 20(3), 553-569.

Furlong, A. and Biggart, A. (1999). Framing choices: a longitudinal study of occupational aspirations among 13 to 16-year olds. Journal of Education and Work, 12(1), 21-35.

Furlong, A. and CartmeL, F. (2004). Vulnerable Young Men in Fragile Labour Markets: Employment, Unemployment and the Search for Long-term Security. York: York Publishing.

Godfrey, C., Hutton, S., Bradshaw, J., Coles, B., Craig, B. and Johnson, J. (2002). Estimating the cost of being 'Not in education, employment or training' at age 16-18 (Research Report No. RR346). Colegate, Norwich: Queen's Printer for Department for Education and Skills.

GPO and KEADIK, (2012). Project: Absents' Barometer. Detection, categorization and empirical grounding of policy proposals for tackling a new form of social vulnerability: The NEETs (Young People Not in Education, Employment or Training)", Deliverable 3.1a: Report of the NEETs' distribution by gender, intermediate ages-categories, ethnocultural origin, educational level and the distribution by administrative region (first phase of quantitative research) (in Greek).

GPO and KEADIK, (2013). Project: Absents' Barometer. Detection, categorization and empirical grounding of policy proposals for tackling a new form of social vulnerability: The NEETs (Young People Not in Education, Employment or Training). Deliverable 3.1b: Report of the NEETs' didtribution by administrative region and district (second phase of quantitative research). "Presentation and analysis of the findings of the quantitative research" (in Greek).

Gregg, P. \& Tominey, E. (2005). The wage scar from youth unemployment. Labour Economics, 12(4), 487-509.

Hill, J. (2003). Young people not in education, training or employment. Key indicators. Wellington: Ministry of Social Development.

INTERNATIONAL LABOUR OFFICE, (2013). Global Employment Trends for Youth 2013: A generation at a risk. Geneva: ILO. Available online at: 
http://www.ilo.org/wcmsp5/groups/public/---dgreports/---dcomm/documents/publication/wc ms_212423.pdf

Inui, A. (2009). NEETs, freeters and flexibility. Reflecting precarious situations in the new labour market, in A. Furlong (Ed.), Handbook of Youth and Young Adulthood. New perspectives and agendas Oxon: Routledge (pp. 176-181),. Available online at: http://www.google.gr/books?hl=el\&lr=\&id=jwHvDIm-TToC\&oi=fnd\&pg=PA176\&dq=relate d:Hfqbosp4rZ8J:scholar.google.com/\&ots=QhPjmMgJKv\&sig=sqzYnRqh2GUULIBeHxljlv aairk\&redir_esc $=\mathrm{y} \# \mathrm{v}=$ onepage $\& \mathrm{q} \& \mathrm{f}=$ false

Kalerante, E., Kyridis, A. \& Fotopoulos, N. (2009). The skills society. Proceedings of the $2^{\text {nd }}$ International Conference of Greek Sociological Society (EKE), Athens: EKE (in Greek).

KANEP/ GSEE, (2013). The fundamentals of education. The Greek higher education. Part A. Athens: KANEP/ GSEE.

KEADIK \& KANEP/ GSEE, (2013). Absents' Barometer. Detection, categorization and empirical grounding of policy proposals for tackling a new form of social vulnerability: The NEETs (Young People Not in Education, Employment or Training). Deliverable 4.4b: Report with the final findings and the conclusions of the qualitative research and classification categories (in Greek).

Kelpanidis, M. (2000). Welfare State and Education. Thessaloniki: Kyriakidis Brothers (in Greek)

Kokkinos, G. (2013). Youth and NEET: What reveals the recent research of Eurofound about the "future of Europe". Which is the situation in Greece? Athens: KANEP/ GSEE. Available online http://www.kanep-gsee.gr/content/neoi-kai-neet-ti-apotyponei-prosfati-ereyna-toy-eurofoundgia-mellon-tis-eyropis-poia-einai, (in Greek)

Kotroyannos, D., Tzagkarakis, S., Kamekis, A. \& Chourdakis, M. (2013), "Presentation of the findings of qualitative interviews and the role of welfare state", in N. Papadakis (ed.), Absents' Barometer: The NEETs (Young People Not in Education, Employment or Training) in Greece. Athens: Sideris, pp. 105- 208 (in Greek)

Kyridis, A. (1997). The Greek educational inequality and the entrance to the University (1955-1985). Athens: Gutenberg (in Greek).

Kyridis, A. and Drossos, V. (2001). Thirty years inequality in Greek Education. Contemporary Education, 118, 68-79 (in Greek).

Kyridis, A., Aggelaki, C., Mavrikaki, E. and Smaga, S, (1998). "Operational conditions of the public schools in Greece - Infrastructure $-1^{\text {st }}$ Part: Early Childhood Education. Contemporary Education, 104, pp.78-88 (in Greek).

Kyridis, A., Aggelaki, C., Mavrikaki, E. and Smaga, S, (1999a). Operational conditions of the public schools in Greece - Infrastructure $-2^{\text {nd }}$ Part: The Primary Schools", Contemporary Education, 105, 83-92 (in Greek). 
Kyridis, A., Aggelaki, C., Mavrikaki, E. and Smaga, S, (1999b). Operational conditions of the public schools in Greece - Infrastructure $-3^{\text {rd }}$ Part: The Public Lower Secondary Schools, Contemporary Education, 106, 57-65 (in Greek).

Kyridis, A., Aggelaki, C., Mavrikaki, E. and Smaga, S, (1999c). Operational conditions of the public schools in Greece - Infrastructure $-3^{\text {rd }}$ Part: The Public General Upper Secondary Schools. Contemporary Education, 107, 91-99 (in Greek).

Kyridis, A., Mavrikaki, E. \& Neroutsos, A. (1995). A contribution to the study of the Greek educational inequality based on the statistics of the Higher Education (time period 1984-1991). Contemporary Education, 76, 29-37 (in Greek).

Kyridis, A., Papadakis, N., Fotopoulos, N., Chronopoulou, A. \& Zagkos, C. (2011). Filling in the Implementation Gap? Problems in the Greek Educational System - An Evidence-based Explanatory Framework and Critical Reflections. Current Issues in Education (CIE), 14(3), 1-19.

Kyridis, A., Tsakiridou, H., Zagkos, C., Koutouzis, M. \& Tziamtzi, C., (2011). Educational inequalities and school dropout in Greece. A regional issue. International Journal of Education, 3(2), 1- 15.

Macdonald, R. (2011). Youth transitions, unemployment and underemployment. Plus ça change, plus c'est la même chose?' Journal of Sociology, 47(4), 427-444.

Panagiotopoulos, N. (2005). The Unemployed Grief. Athens: Polytropon. (in Greek)

Pandis, P. \& Zagkos, C. (2013). Social and demographic characteristics of NEETs: The case of Greece. In N. Papadakis (ed.), Absents'Barometer: The NEETs (Young People Not in Education, Employment or Training) in Greece. Athens: Sideris, pp. 109- 120 (in Greek).

Papadakis, N. (2012). Towards a paradigm shift? The recent economic downturn, the EU 2020 strategy (2010 - 2020), and the new EU policy in Education. Training and Lifelong Learning. Seminar within the framework of the LLAKES Seminars, London: Institute of Education/ LLAKES Research Centre, June 2012

Papadakis, N. (2013). NEETs in Europe: Convergences and divergences, in N. Papadakis (ed.), Absents' Barometer: The NEETs (Young People Not in Education, Employment or Training) in Greece. Athens: Sideris, pp. 15- 75 (in Greek).

Papadakis, N. (2014). Public Policies on Education and Training. On the epistemological and methodological components of the field and the European state of play, in A.I.-D. Metaxas (ed.), Political Science: Interdisciplinary and Critical Approach of Politics, Athens: Sideris (under publication) (in Greek).

Papargyris, A. (2013). Presentation and analysis of the results of quantitative research, in N. Papadakis (ed.), Absents' Barometer: The NEETs (Young People Not in Education, Employment or Training) in Greece. Athens: Sideris (in Greek).

Papatheodorou, C. \& Papanastasiou, S. (2010). Intergenerational transmission of poverty in 


\section{Macrothink}

Greece and the EU: Theoretical approaches and empirical analysis. Athens: INE/GSEE.

PEDAGOGICAL INSTITUTE, (2008). Research of the Employment of the Graduates of the Upper Secondary Education (TEE-Unified Upper Secondary School). Athens: MINERVA (in Greek).

Pirgiotakis, Y. (1998). Socialization and educational inequalities. Athens: Grigoris.

Popham, I. (2003). Tacking NEETs: Research on Action and Other Factors that Can Contribute to a Reduction in the Numbers of Young People Not in Education, Employment or Training (NEET). DfES Publications: Nottingham.

Rifkin, J. (2003). Rethinking the Future of Employment in the E.U. Proceedings of the European Conference on "The future of work. Key challenges for the European Employment Strategy”. Athens, 13-14 February 2003.

Roberts, S. (2010). Misrepresenting choice biographies? Journal of Youth Studies, Vol. 13, No.1, pp. 137-149.

Roberts, S. (2011). Beyond 'Neet' and tidy pathways: Considering the 'missing middle' of youth transition studies. Journal of Youth Studies, 14(1), 21-40.

Roberts, S. (2012). One step forward, one step Beck: a contribution to the ongoing conceptual debate in youth studies. Journal of Youth Studies, 15(3), 389-401.

Schoon, I. (2007). Adaptations to changing times: agency in context. International Journal of Psychology, 42(2), 94-101.

Shildrick, T. \& Macdonald, R. (2006). In defense of subculture: Young people, leisure and social divisions. Journal of Youth Studies, 9(2), 125-140.

Strauss, A. \& Corbin, J. (1990). Basics of Qualitative Research. Grounded Theory. London: Sage.

THE PRINCE'S TRUST, (2007). The Cost of Exclusion: Counting the cost of youth disadvantage in the UK. The Prince's Trust.

Tsakiridou, H., Kyridis, A. \& Vamvakidou, I. (2011). Women in Greece: issues of social exclusion and social vulnerability. What Greek university students believe about women's position in the Greek society? International Conference Proceedings, Human Rights and Violent Behaviour: The Social and Educational Perspective, University of Cyprus, pp. 273 $-292$.

Tsiolis, G. (2006). Life stories and biographical narratives - The biographical approach in qualitative sociological research. Athens: Kritiki.

Williamson, H. (2005). Young People and Social Inclusion. An overview of policy and practice, in M. Barry (ed.), Youth Policy and Social Inclusion. Critical Debates with Young People. London: Routledge.

Woodman, D. (2009). The mysterious case of the pervasive choice biography: Ulrich Beck, 
structure/agency, and the middling state of theory in the sociology of youth. Journal of Youth Studies, 12(3), 243-256.

Yates, S. \& Payne, M. (2006). Not so NEET? A Critique of the Use of 'NEET' in Setting Targets for Interventions with Young People. Journal of Youth Studies, 9(3), 329-344. 